\title{
Tensile Behavior and Cyclic Creep of Continuous Fiber-Reinforced Glass Matrix Composites at Room and Elevated Temperatures
}

\author{
A.R. Boccaccini, G. West, J. Janczak, M.H. Lewis, and H. Kern
}

\begin{abstract}
In this study we investigated the stress-strain behavior at room and elevated temperatures and the tensile creep and cyclic creep response of a unidirectional SiC fiber-reinforced aluminosilicate glass matrix composite. The interfacial condition of the as-received material was measured by a push-out indentation technique. The stress-strain behavior was that expected for this kind of composite, i.e. "pseudoductile" behavior with extensive fiber "pull-out" at room temperature and brittle failure at intermediate temperatures $\left(750^{\circ} \mathrm{C}\right)$ due to oxidation embrittlement. The stiffness of the composite at $750^{\circ} \mathrm{C}$ was analyzed for different loading rates, highlighing the influence of the loading rate on apparent composite stiffness, due to matrix softening. The creep studies were conducted at temperatures above and below the softening temperature of the glass $\left(T_{\mathrm{g}}, 745^{\circ} \mathrm{C}\right)$ in air. The cyclic creep experiments showed the existence of extensive viscous strain recovery during the unloading period. The creep strain recovery was quantified using strain recovery ratios. These ratios showed a slight dependence on the temperatures investigated $\mathbf{7 0 0}$ and $750^{\circ} \mathrm{C}$ ). The crept composites retained their "graceful" fracture behavior only partially after testing, indicating that oxidation of the fiber/matrix interface due to oxygen diffusion through the matrix occurred in the peripheral area of the samples.
\end{abstract}

\section{Keywords}

composites, cyclic creep, glass matrix, strain recovery

\section{Introduction}

CONTINUOUS fiber-reinforced ceramic matrix composites and related glass and glass-ceramic matrix composites are candidate materials for various structural, high-temperature, and other specialized applications (Ref 1-7). The reason for the interest in these materials is their improved mechanical properties, especially fracture toughness and non-catastrophic failure mode, when compared to those of monolithic materials. Possible applications exist for intermediate-temperature-capability composites that are easily processed, such as those with a glass matrix. Such materials must be able to operate under adverse conditions involving creep, cyclic creep, or fatigue loading. Under these loading conditions there may be deformation, interfacial reactions, and matrix microstructural changes, which can lead to increasing microstructural damage and eventually to composite failure. Thus, besides the characterization of the stress-strain response at room and elevated temperatures, knowledge of the creep response of the composite under both monotonic and cyclic loading is important for materials evaluation, because they represent conditions that the components may encounter in service.

A.R. Boccacini and H. Kern, Technische Universität Ilmenau, Fachgebiet Werkstofftechnik, D-98684 Ilmenau, Germany; G. West and M.H. Lewis, Centre for Advanced Materials, Department of Physics, University of Warwick, Coventry CV4 7AL, England; and $J$. Janczak, Swiss Federal Laboratories for Materials Testing and Research, CH-3602 Thun, Switzerland. Dr. Boccaccini is presently at the Institute for Mechanics and Materials, University of California, San Diego, CA 92093, USA.
Work in this field has been conducted by Holmes et al. for $\mathrm{SiC}$ fiber-reinforced calcium aluminosilicate (CAS) glassceramic matrix composites $(\operatorname{Ref} 8)$ and $\mathrm{SiC}$ fiber-reinforced silicon nitride (Ref 9), by West et al. for barium-magnesiumaluminosilicate (BMAS) glass-ceramic matrix composites (Ref 10,11), and by Sun et al. on similar BMAS composites (Ref 12). Overall, the experimental results in the literature suggest that when compared to sustained loading, elevated-temperature cyclic loading can decrease the overall strain accumulation in fiber-reinforced ceramics. This effect should be enhanced when one of the constituents has a high glassyphase content. The decrease in strain is a consequence of viscous strain recovery that occurs during the unloading portion of a creep cycle. This strain recovery effect in fiber-reinforced composites has important implications for the life prediction of components under cyclic loading. The total strain accumulation may be much lower than that observed for sustained creep loading, and therefore life predictions that do not consider the strain recovery component can lead to pessimistic lifetime expectations (Ref 9).

This paper presents results on the tensile stress-strain response at room and elevated temperatures and on the tensile cyclic creep behavior of an aluminosilicate glass matrix composite reinforced with $\mathrm{SiC}$ (Nicalon) fibers. The tests were carried out in air at temperatures near the glass transition temperature $\left(T_{\mathrm{g}}\right)$ of the matrix. The quantification of the strain recovery that took place during cyclic loading was done using creep recovery ratios. The variation of composite stiffness with loading rate at temperature was also investigated.

\section{Experimental Procedure}

The composite material was supplied in the form of plates ( 110 by 110 by $3 \mathrm{~mm}^{3}$ ) by the manufacturer (Schott Glaswerke, Mainz, Germany). Details of the glass matrix composite inves- 
tigated are given in Table 1 . The data shown have been furnished by the manufacturer or were obtained from the literature (Ref 13-15). The fiber volume fraction was 0.42 . The detailed description of the fabrication procedure, which involves a slurry technique for fiber impregnation and densification by hot pressing, can be found in Ref 15 .

The material was available in unidirectional architecture and showed good density with only minor residual porosity. Figure 1 shows a scanning electron microscopy (SEM) image of the material. A push-out indentation technique was employed, as a quality control, on as-received samples to assess the condition of the fiber/matrix interface, known to be crucial for determining the mechanical properties of this type of composite.

These tests were conducted using an in situ SEM indentation apparatus (Touchstone Ltd., USA) (Ref 16). The thickness of the specimens was $350 \mu \mathrm{m}$. A diamond indenter (end diameter $6.8 \mu \mathrm{m}$ ) was used to apply the load on the fibers, and a displacement rate of $0.0625 \mu \mathrm{m} / \mathrm{s}$ was employed. The failure modes were observed by SEM. Twenty fibers were indented and the average interfacial shear stress at the onset of debonding $(\tau)$ was determined. Samples for tensile tests were cut from the as-received plates by means of a diamond milling tool in a computer numerically controlled machine. Specimens with 40 by 4 by $3 \mathrm{~mm}$ gage section were employed. A "dog-bone" test piece, similar to that specified by Holmes (Ref 17), was used with superalloy wedge-shaped warm gripping. Strain measurement was achieved with an MTS low-contact force extensometer. The mechanical behavior of the composite under monotonic load was assessed at room temperature and at a maximum of $800{ }^{\circ} \mathrm{C}$ by tensile testing. Very low contact force was necessary at the temperatures used to prevent sample flexure and creep under the lateral loading imposed by the extensometers.

Creep and cyclic creep tests were conducted using load control with a loading rate of $0.5 \mathrm{MPa} / \mathrm{s}$. The cyclic creep behavior was tested at two temperatures, 700 and $750{ }^{\circ} \mathrm{C}$. Hold times for cyclic creep at load and nominally no load ( $2 \mathrm{MPa}$ ) were equal. One cycle was typically $8 \mathrm{~h}$. The apparent stiffness variation

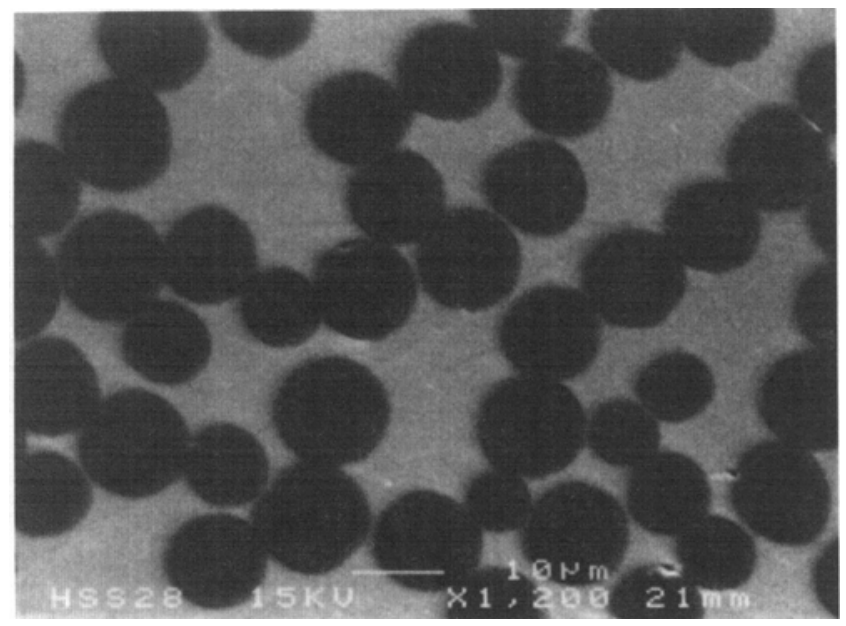

Fig. 1 SEM micrograph of the aluminosilicate glass matrix composite investigated, showing fiber distribution and dense matrix with loading rates from 0.0067 to $13.5 \mathrm{MPa}$ /s was investigated with a minimum of three loading/unloading cycles to $100 \mathrm{MPa}$ at $750^{\circ} \mathrm{C}$. The fracture surfaces of broken samples during tensile tests were observed by SEM. After the cyclic creep tests, some crept samples were tested at room temperature using the same jig described above. The fracture surfaces of these broken samples were also observed by SEM.

\section{Results and Discussion}

\subsection{Interfacial Conditions}

Figure 2 is a typical push-out indentation plot showing the load-time curve at room temperature. The average value of $\tau$ was $18 \mathrm{MPa}$, with subsequent interfacial shear at lower stress (typically 9 to $10 \mathrm{MPa}$ ). Although there was considerable scatter in the determined values, in general, the low stresses measured indicate the presence of a weak (carbon-rich) interface. In-depth microstructural investigations in the composites have shown that the interfacial layer has a thickness of approximately $30 \mathrm{~nm}(\operatorname{Ref} 13,18)$. For the present study, the results of the push-out investigation were solely intended as a quality control for the as-received material to confirm the presence of the weak interface.

\subsection{Tensile Stress-Strain Behavior}

Figure 3 shows typical stress-strain plots for the samples tested at room temperature and at 750 and $800{ }^{\circ} \mathrm{C}$. Consider-

Table 1 Properties of the constituents of the aluminosilicate glass matrix composite investigated

\begin{tabular}{lcc}
\hline Properties & $\begin{array}{c}\text { Aluminosilicate matrix } \\
\text { (code 8409, Schott) }\end{array}$ & $\begin{array}{c}\text { SiC fiber } \\
\text { (Nicalon) }\end{array}$ \\
\hline Density, g/cm ${ }^{3}$ & 2.51 & 2.55 \\
Young's modulus, GPa & 87 & 200 \\
Poisson's ratio & 0.24 & 0.20 \\
Coefficient of thermal expansion, & 4.1 & 3.35 \\
$10^{-6} /{ }^{\circ} \mathrm{C}$ & 745 & $\ldots$ \\
Transformation temperature, ${ }^{\circ} \mathrm{C}$ & & \\
Source: Ref $13-15$ & & \\
\hline
\end{tabular}

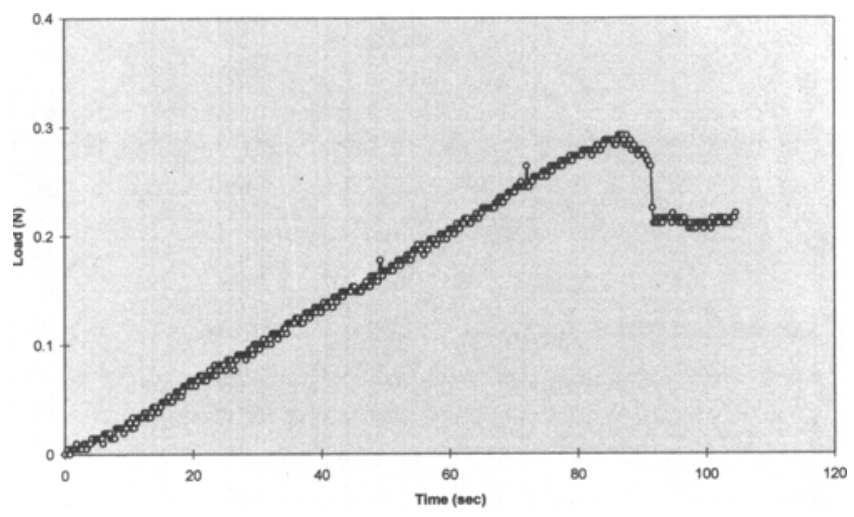

Fig. 2 Typical load-time plot during indentation push-out test. The diameter of the pushed fiber was $14.8 \mu \mathrm{m}$. 
able "pull-out" and "graceful" failure mode were apparent in samples broken at room temperature, behavior to be expected due to the presence of a weak fiber/matrix interface.

Figure 4 shows a SEM micrograph of a fracture surface that demonstrates the pull-out mechanism. The room-temperature strength was $355 \mathrm{MPa}$ and the Young's modulus was $135 \mathrm{GPa}$. At $750^{\circ} \mathrm{C}$, "brittle" fracture with minimal pull-out was evident. It has been shown in the literature $(\operatorname{Ref} 13,19)$ that interfacial oxidation occurs in similar composites, starting at temperatures between 600 and $650{ }^{\circ} \mathrm{C}$. Consequently, the fibers become strongly bonded to the matrix phase, and hence it is more energetically favorable for impinging cracks to go through the fibers rather than around them, with subsequent debonding leading to the limited fiber pull-out observed. The fracture strength of $342 \mathrm{MPa}$ at $800^{\circ} \mathrm{C}$, well above $T_{\mathrm{g}}$, was surprisingly high. This strength was coupled with a considerable loss of composite stiffness. The stiffness of $84 \mathrm{GPa}$ can be explained by a rule-of-mixtures calculation, assuming a Young's modulus of the fibers of $200 \mathrm{GPa}$ (Table 1) and a zero contribution to stiffness from the matrix. This behavior is to be expected, since the testing temperature was higher than the $T_{\mathrm{g}}$ of the matrix $\left(745^{\circ} \mathrm{C}\right)$. The similar strengths at room temperature and at 800 ${ }^{\circ} \mathrm{C}$ indicate that the strength is dependent on the in situ fiber

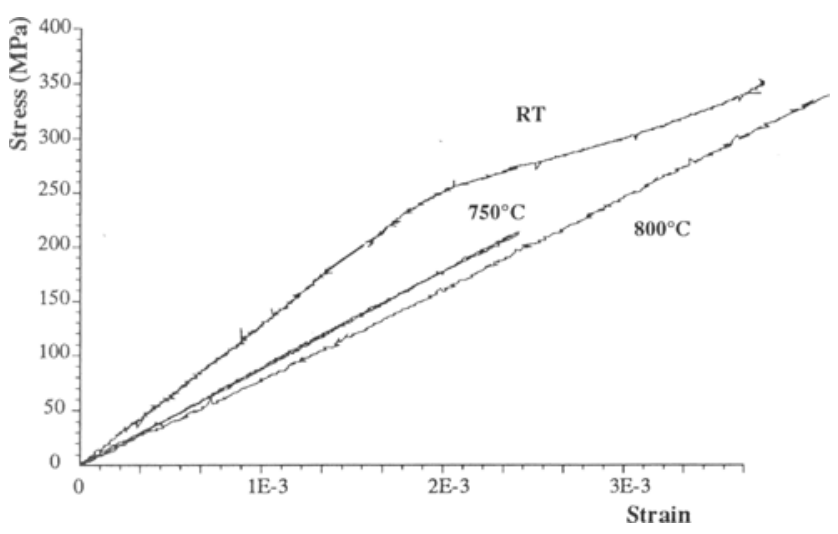

Fig. 3 Typical tensile stress-strain plots for samples tested at (a) room temperature, (b) $750^{\circ} \mathrm{C}$, and (c) $800^{\circ} \mathrm{C}$

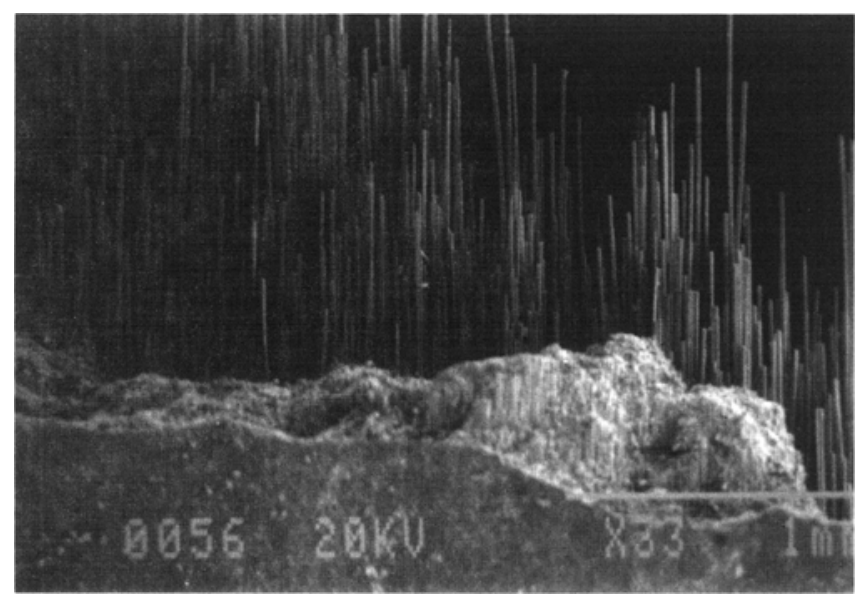

Fig. 4 SEM micrograph of the fracture surface of a sample broken in tension at room temperature, showing extensive fiber pullout compatible with the weak interfacial bond found in Fig. 2 strength. The much lower strength at $750^{\circ} \mathrm{C}$ can be attributed to matrix cracking and subsequent oxygen ingress during crack growth, which made the composite strength matrix dominant. At $800^{\circ} \mathrm{C}$ the modulus remains constant to failure, suggesting that the matrix flows and does not crack, thereby shielding the fibers. Failure faces at room temperature and at $800^{\circ} \mathrm{C}$ show similar levels of pull-out. However, the $800{ }^{\circ} \mathrm{C}$ test shows a thin, brittle planar region adjacent to the specimen surface. This embrittled outer region has been atrributed to oxygen diffusion through the matrix. The depth of this zone increases with exposure time, as shown elsewhere (Ref 18$)$.

\subsection{Stiffness versus Loading Rate Behavior at High Temperatures}

It was demonstrated in the section above that the composite ultimate strength can be dominated by the matrix properties. Higher strengths are realized well above the $T_{\mathrm{g}}$ of the matrix by either crack blunting or load shedding from the matrix to the fibers $(\operatorname{Ref} 8,9)$. The delayed matrix cracking ensures that oxygen is excluded from the composite interior for longer periods; hence, composite strength is enhanced. The load transfer is temperature related and also can be increased by reducing the loading rate. For the range of loading rates investigated $(0.0067$ to $13.5 \mathrm{MPa} / \mathrm{s}$ ) at $750{ }^{\circ} \mathrm{C}$, the composite stiffness showed a spread of $31 \mathrm{GPa}$, as shown in Fig. 5. At the lowest rate the composite stiffness of $87 \mathrm{GPa}$ approximated that attributable to the fibers alone ( $84 \mathrm{GPa}$, according to a rule-of-mix tures calculation; see the previous section), compared to $118 \mathrm{GPa}$ at the highest loading rate. Although the ultimate strengths have not been evaluated for the different loading rates, a similar study on BMAS/Tyranno fiber composite has shown greatly improved strengths at low loading rates when the matrix exhibits creep or viscous flow (Ref 18 ).

\subsection{Tensile Cyclic Creep Behavior}

Experiments were conducted to study the creep strain recovery behavior of the composites in tensile mode. During the unloading period of each cycle the composites exhibited

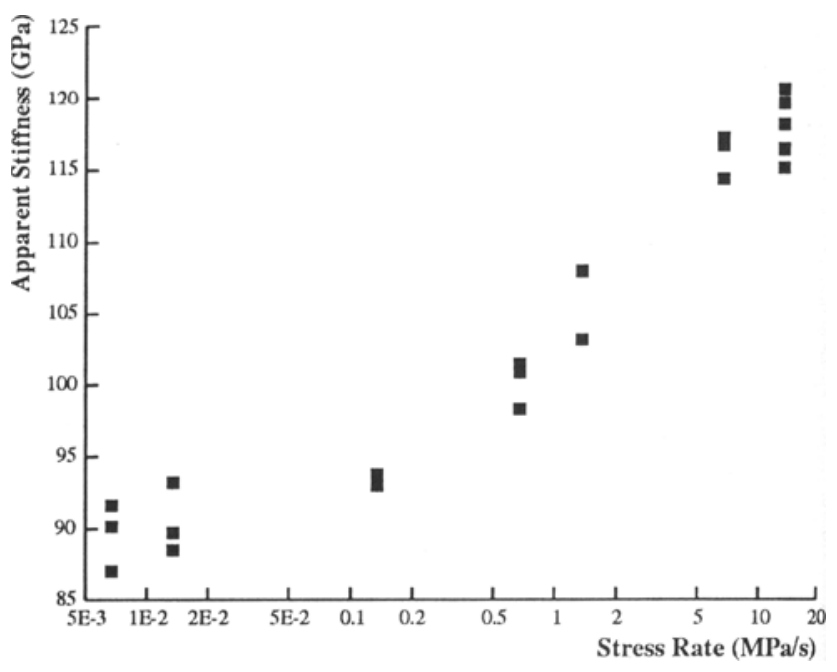

Fig. 5 Plot indicating the change in composite stiffness with loading rate at $750^{\circ} \mathrm{C}$ 
extensive viscous strain recovery for the two temperatures investigated. Figure 6 shows, as an example of this behavior, the cyclic creep response of the material at a stress level of 100 MPa at $750^{\circ} \mathrm{C}$. As pointed out by Holmes et al. (Ref 8, 9), the extent of strain recovery in ceramic matrix composites depends on the residual stresses developed in the material upon the loading/unloading cycles. In addition to the intrinsic recovery mechanisms of the constituents, the residual stress state that exists in a composite material after unloading can provide a further driving force for strain recovery. These residual stresses depend on the composite architecture, mismatch in elastic constants, and thermal expansion between the matrix and the fibers, and on the test temperature, applied stress, and accumulated creep strain as well. Moreover, strain recovery, being governed by a load transfer and stress redistribution mechanism, will be dependent on the degree of interfacial bonding at the working temperature. The quantification of creep strain recovery during creep-fatigue loading can be carried out conveniently using the recovery ratios introduced by Holmes et al. ( $\operatorname{Ref} 8,9)$ : the creep-strain recovery ratio, $R_{\mathrm{cr}}$ and the total-strain recovery ratio, $R_{\mathrm{t}}$. These ratios can be calculated according to the following relations:

$$
\begin{aligned}
& R_{\mathrm{cr}}=\frac{\varepsilon_{\mathrm{cr}, \mathrm{R}}}{\varepsilon_{\mathrm{cr}}} \\
& R_{\mathrm{t}}=\frac{\left(\varepsilon_{\mathrm{el}, \mathrm{R}}+\varepsilon_{\mathrm{cr}, \mathrm{R}}\right)}{\varepsilon_{\mathrm{t}}}
\end{aligned}
$$

where $\varepsilon_{\mathrm{cr}, \mathrm{R}}$ represents the creep strain recovered during a particular unloading cycle, $\varepsilon_{\mathrm{cr}}$ represents the creep strain for the cycle, $\left(\varepsilon_{\mathrm{el}, \mathrm{R}}+\varepsilon_{\mathrm{cr}, \mathrm{R}}\right)$ represents the total strain recovered within a particular cycle, and $\varepsilon_{\mathrm{t}}$ is the total accumulated strain for the experiment. Note that the creep strain recovery ratio, $R_{\mathrm{cr}}$ considers only time-dependent creep strains during loading and unloading, while the total strain recovery ratio, $R_{\mathrm{t}}$, also includes the elastic components of strain during loading and unloading. Table 2 shows the calculated recovery ratios for the first cycles of cyclic creep tests of aluminosilicate glass matrix composites at 700 and $750^{\circ} \mathrm{C}$ and at a maximum stress level of $100 \mathrm{MPa}$. The minimum stress was $2 \mathrm{MPa}$ and the holding time for each cycle was $4 \mathrm{~h}$.

Although the authors are not aware of previous studies on cyclic creep in tensile mode on similar glass matrix materials, the data on creep recovery ratios may be compared for different materials, since their definitions are of general validity. The creep recovery ratios for the glass matrix composite investi-

Table 2 Creep strain recovery ratios for tensile cyclic

\begin{tabular}{|c|c|c|c|c|c|c|}
\hline \multirow{2}{*}{$\begin{array}{l}\text { Strain recovery } \\
\text { ratios }\end{array}$} & \multicolumn{3}{|c|}{ At $750^{\circ} \mathrm{C}$} & \multicolumn{3}{|c|}{ At $700^{\circ} \mathrm{C}$} \\
\hline & Cycle 1 & Cycle 2 & Cycle 3 & Cycle 1 & Cycle 2 & Cycle 3 \\
\hline$R_{\mathrm{cr}} \%$ & 55 & 73 & 81 & 61 & 74 & 88 \\
\hline$R_{\mathrm{f}}, \%$ & 82 & 81 & 80 & 93 & 88 & 87 \\
\hline
\end{tabular}
creep of aluminosilicate glass matrix composite materials gated here are very high, and they are similar to the values reported for the tensile cyclic creep of SiC/CAS (Ref 8) and the flexural cycle creep of BMAS/SiC composites (Ref 10-12). The increase in $R_{\mathrm{cr}}$ with the number of cycles is caused by a lower level of stress transfer from the matrix (which is placed in compression after unloading) to the fibers on subsequent cycles. $R_{\mathrm{t}}$ has a decreasing dependence with the number of cycles as the accumulated strain increases. The presence of extensive creep recovery is a positive phenomenon that leads to an overall decrease of the accumulated creep strain. It should be taken into account, therefore, when predicting the life of components that will be loaded under cyclic creep conditions.

Some crept samples were tested in tension at room temperature upon finishing the cyclic creep tests. They failed, showing pull-out of the fibers; however, the pull-out was limited to the central area of the sample cross section. This behavior is shown in Figure 7, a SEM micrograph of the fracture surface of a sample crept at a stress level of $100 \mathrm{MPa}$. Thus, while the central area shows the pull-out of fibers, indicative of the weak (carb-

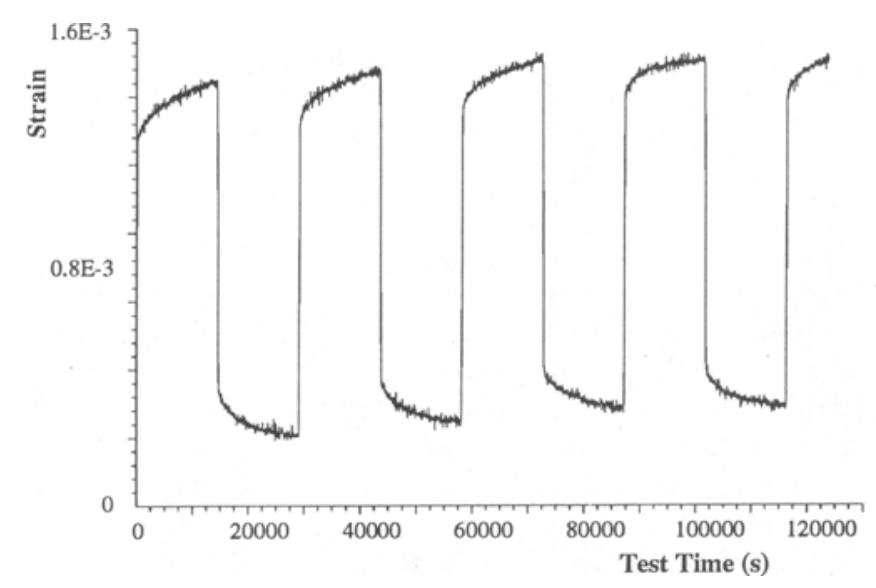

Fig. 6 Materials response under tensile cyclic creep loading conditions at $750^{\circ} \mathrm{C}$, showing creep recovery behavior. Maximum stress, $100 \mathrm{MPa}$; minimum stress, $2 \mathrm{MPa}$ (first cycles)

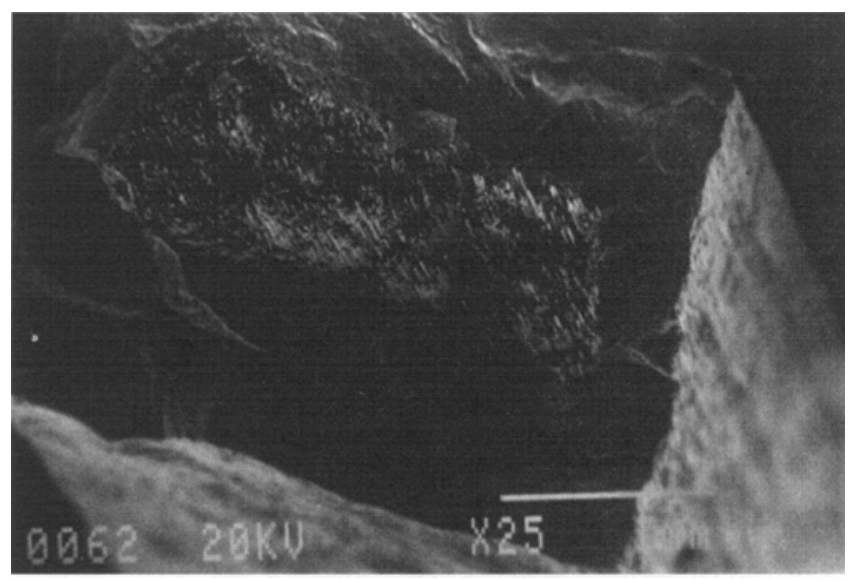

Fig. 7 SEM micrograph of the fracture surface of a sample crept under the conditions of Fig. 6 and tested after the cyclic creep loading in tension at room temperature. Note that there was only partial pull-out of the fibers located in the center of the sample. 
on-rich) interface, the periphery shows a flat fracture path, indicative of fiber fracture due to strong bonding at the interface and, eventually, fiber degradation due to oxidation. This result indicates that embrittlement of the composite occurred during high-temperature exposure due to oxygen diffusion through the matrix.

\section{Conclusions}

The mechanical properties, at room and high temperatures, of a unidirectional $\mathrm{SiC}$ fiber-reinforced aluminosilicate glass matrix composite were investigated using a range of tests and techniques. The stress-strain behavior was that expected for this kind of composite, i.e. "pseudoductile" behavior with extensive fiber pull-out at room temperature and at $800^{\circ} \mathrm{C}$, and brittle failure at intermediate temperatures due to oxidation embrittlement. The interfacial condition of the as-received material was investigated by a push-out indentation technique and the presence of a weak interface was detected. The stiffness of the composite at $750^{\circ} \mathrm{C}$ was shown to be strongly dependent on the loading rates, highlighing the importance of strain rate on mantainance of matrix integrity due to time-dependent matrix stress relaxation. Cyclic creep studies were conducted at temperatures above and below $T_{\mathrm{g}}\left(745^{\circ} \mathrm{C}\right)$ in air. The cyclic creep experiments showed the existence of extensive viscous strain recovery during the unloading period. The creep strain recovery was quantified using strain recovery ratios. The ratios are high for the material investigated here and are comparable to previous results on glass-ceramic matrix composites. Moreover, the creep recovery ratios are negligibly dependent on the temperature in the investigated range $\left(700\right.$ to $\left.750^{\circ} \mathrm{C}\right)$. Because of the great importance of creep recovery in life prediction calculations and design of components for high-temperature applications, further work will be focused on the dependence of the strain recovery on the loading history for these materials. The crept composites retained their "graceful" fracture behavior only partially after testing, indicating that oxidation of the fiber/matrix interface due to oxygen diffusion through the matrix affected the outer layer of the composite.

\section{Acknowledgments}

The authors acknowledge the financial support of the European Commission (DGXII) with the provision of Brite-Euram contracts (BE4610 and BRE2 CT94 3064). Dr. W. Beier and Dr. J. Heinz (Schott Glaswerke, Mainz, Germany) are acknowledged for supplying the materials investigated.

\section{References}

1. K.M. Prewo and J.J. Brennan, High-Strength Silicon Carbide Fibre-Reinforced Glass-Matrix Composites, J. Mater. Sci., Vol 15, 1980, p 463-468
2. A.G. Evans and D. B. Marshall, The Mechanical Behaviour of Ceramic Matrix Composites, Overview 85, Acta Metall., Vol 37, 1989, p 2657-2683

3. K.M. Prewo, Fibre Reinforced Glasses and Glass-Ceramics, Glasses and Glass-Ceramics, M.H. Lewis, Ed., Chapman and Hall, London, 1989, p 336-368

4. J.J. Brennan, Interfacial Chemistry and Bonding in Fibre Reinforced Glass-Ceramic Matrix Composites, Tailoring Multiphase and Composite Ceramics, R.E. Tressler, G.L. Messing, and C.G. Newnham, Ed., Plenum Press, 1988, p 387-400

5. V.S.R. Murthy, L. Jie, and M.H. Lewis, Interfacial Microstructure and Crystallisation in SiC-Glass-Ceramic Composites, Ceram. Eng. Sci. Proc., Vol 10, 1989, p 938-951

6. S.M. Bleay, V.D. Scott, B. Harris, R.G. Cooke, and F.A. Habib, Interface Characterisation and Fracture of Calcium Aluminosilicate Glass-Ceramic Reinforced with Nicalon Fibres, J. Mater. Sci., Vol 27, 1992, p 2811-2822

7. A.G. Evans and F.W. Zok, Review: The Physics and Mechanics of Fibre-Reinforced Brittle Matrix Composites, J. Mater. Sci., Vol 29, 1994, p 3857-3896

8. X. Wu and J.W. Holmes, Tensile Creep and Creep-Strain Recovery Behavior of Silicon Carbide Fiber/Calcium Aluminosilicate Matrix Ceramic Composites, J. Am. Ceram. Soc., Vol 76, 1993, p 2695-2700

9. Y.H. Park and J.W. Holmes, Finite Element Modelling of Creep Deformation in Fibre-Reinforced Ceramic Composites, J. Mater. Sci., Vol 27, 1992, p 6341-6351

10. G. West, A.R. Boccaccini, and D.M.R. Taplin, Creep and CreepFatigue Behaviour of Continuous Fibre Reinforced Glass-Ceramic Matrix Composites, Mater.wiss. Werkst.tech., Vol 26, 1995, p 368-373

11. G. West, A.R. Boccaccini, D.M.R. Taplin, and M.H. Lewis, Cyclic Creep Response of Continuous Fibre Reinforced Glass-Ceramic Matrix Composites, Proc. Seventh European Conference on Composite Materials, Vol 1, Woodhead Publ. Ltd., London, 1996, p 455-460

12. E.Y. Sun, S.R. Nutt, and J.J. Brennan, Flexural Creep of Coated SiC-Fiber Reinforced Glass-Ceramic Composites, J. Am. Ceram. Soc., Vol 78, 1995, p 1233-1239

13. B. Meier, C. Franz, G. Grathwohl, H. Iwanek, and K. Przemeck; Creep Behaviour of SiC-Fibre (Nicalon) Reinforced Glasses, Advanced Structural Fibre Composites, P. Vincenzini, Ed., Techna Srl, Faenza, Italy, 1995, p 743-750

14. "Technical Glasses," product information, Schott Glaswerke, Mainz, Germany, 1990

15. W. Beier, J. Heinz, and W. Pannhorst, Langfaservertärkte Gläser und Glaskeramiken-eine neue Klasse von Konstruktionswerkstoffen, VDI Berichte, Vol 1021, 1993, p 255-267 (in German)

16. J. Janczak, G. Buerki, and L. Rohr, Interfacial Characterization of MMCs and CMCs using a SEM-Pushout Technique, Key Enginering Materials, Tran Tech Publications, Switzerland, Vol 127-131, 1997, p 623-630

17. J.W. Holmes, Tensile Creep Behaviour of a Fibre Reinforced SiC-Si3 $\mathrm{N}_{4}$ Composite, J. Mater. Sci., Vol 26, 1991, p 1808-1814

18. G. West, Ph.D. thesis, University of Warwick, Coventry, England, in preparation, 1997

19. S. Sutherland, K.P. Plucknett, and M.H. Lewis, High Mechanical and Thermal Stability of Silicate Matrix Composites, Compos. Eng., Vol 5, 1995, p 1367-1378 